\title{
A Review on Ecosystem Health Research: A Visualization Based on CiteSpace
}

\author{
Hui Yang, Xuexin Shao and Ming $\mathrm{Wu}$ * \\ Wetland Ecosystem Research Station of Hangzhou Bay, Research Institute of Subtropical Forestry, \\ Chinese Academy of Forestry, Hangzhou 311400, China \\ * Correspondence: hangzhoubay@126.com
}

Received: 11 July 2019; Accepted: 4 September 2019; Published: 8 September 2019

\begin{abstract}
With ecological environments that play vital roles in sustaining human communities worsening, ecological health has drawn extensive attention from scholars and practitioners. It is obvious that research results relevant to ecological health are increasing. This study applies scientometric methods to evaluate the current situation of ecological heath research, and explore the developing trends of ecological health research based on the literature data obtained from the Web of Science Core Collection database. Study results generated in this paper could clearly answer the three following questions: (1) What are the subject categories that scholars are most concerned about in the ecological health research area? (2) Which authors and journals are the most representative in this area? On which research areas do researchers focus at different stages? What are the documents that attract scholarly attention? (3) What are the representative keywords in the different periods? What are the research focuses and the new emerging trends in the field of ecological health? In general, this paper provides an effective research method to evaluate the performance of ecological health research. The paper may assist new researchers to pick out the most relevant journals, articles, keywords, and influential authors, consequently assisting researchers to be at the research frontier in the ecological health field, and finally, to establish future research directions.
\end{abstract}

Keywords: aquatic ecosystem; hot topics; emerging trends; scientometric methods

\section{Introduction}

With the population increasing and the economy growing, the environment and resources have become highly stressed, and the deterioration of the environment is severely threatening human existence and development $[1,2]$. On these grounds, ecosystem health closely related to ecological, economic, and human health has greatly attracted scientific interest and is rapidly growing, involving a wide range of interdisciplinary fields. Many definitions for ecosystem health have been proposed, but there is no unified standard. Constanza et al., summarized a range of proposed concepts and indicated that an ecosystem is healthy and disease is absent if it is stable and sustainable; that is to say, the ecosystem has the ability to maintain its vigor and is automatically resilient when facing additional stress [3]. Mageau et al., elaborated upon this definition and proposed operational measures of ecosystem health comprised of vigor, organization, and resilience [4]. However, Rapport et al., considered the definitions that only emphasized the ecological aspects of ecological health to not be comprehensive enough, and took the human health indicators into account, based on the former definition [5]. Generally speaking, ecosystem health is a comprehensive and dynamic concept and its definition is not unique, which may be related to the fact that researchers defined this concept from different perspectives. There are a number of studies on ecological health, including those on marine resources, ecological indicators, or biological assessments, and river and urban-ecosystem 
health studies. According to a statistical analysis of the existing literature, we found that the number of publications on ecological health has been steadily increasing in recent years.

With the quantity of research in mind, many analysts have summarized some ecological-health research results by traditional methods. Various perspectives have been reflected in these analysis results; for example, Tett et al., reviewed research situations based on a literature series related to ecosystem health and introduced a framework for monitoring the state of marine ecosystem health [6]. O'Brien et al., systematically reviewed studies measuring ecosystem health, analyzed these studies' temporal and spatial distributions, and examined the assessment methods evaluating ecosystem health in freshwater and estuarine ecosystems [7]. Li et al., provided us with views of ecosystem health assessment using remote sensing in dynamic temporal and spatial scales, and presented future perspectives, current opportunities and challenges [8]. Su et al., guided us to understand the development vein of urban ecosystem health assessment [9]. Despite these studies, most analyses are still incomplete, and now out of date. Generally speaking, research analyzing the current state and the development trends of this area is rare.

Scientometrics is quantitative analysis about a process, and the inputs and outputs of scientific and technological activities, to understand the knowledge mapping of scientific fields, and the developing status in relevant scientific and technological domains based on the methods of computing technology and social statistics [10]. In the past few years, it has become a universal phenomenon, and many researchers are enthusiastic about using the scientometric method to find out about hot topics and the evolving development trends in a relevant domain. Information visualization software CiteSpace is playing an increasingly important role in knowledge management activities [11]. Contrasting with other common types of information visualization software, for instance, ArnetMiner, PaperLens, and TDA, CiteSpace uses integration that can achieve cluster analysis, social-network analysis, and multidimensional scaling. In addition, CiteSpace has advantages in detecting emerging trends of a research frontier, and analyzing the relationship between a research frontier and the knowledge basis, and the internal relationship between different research frontiers [12]. In view of this series of advantages, CiteSpace is now applied in a wide range of fields and has basically been accepted by users who want to have a general understanding of their research area [13]. Yu et al., adopted types of the scientometric-analysis methods, such as cluster analysis and burst analysis, to analyze the current state and explore the development tendencies of the carbon-emission trading domain [14]. Chen made a scientometric review of the literature concerning major aspects of science mapping to identify major areas, intellectual milestones, evolutionary stages of major specialties, and transition dynamics from one specialty to another [15]. Jiang et al., applied the scientometric method, cluster analysis, and the document-sorting method to identify the hot topics and dynamic developing stages of urban-planning research under the influence of climate change [16]. Huang et al., developed an assessment-index system to analyze the relationship between rural resilience and land-use policy based on a co-citation network and research clusters [17].

Given the increasing significance of ecological health and the advantages of CiteSpace, it is urgent and necessary to analyze the current status and explore the evolving trends of the ecological-health field with the help of this tool. Therefore, we aimed to visually demonstrate knowledge structures and developments within ecological-health research from 1989 to 2018 using CiteSpace. More specifically, we mainly used co-citation analysis and co-occurrence analysis to (1) summarize the annual variations of publications and identify major subject categories; (2) detect the influential authors and journals, the main research areas, and representative documents; and (3) determine the emerging hot topics of ecological health research, and finally, predict development trends. 


\section{Materials and Methodology}

\subsection{Data Acquisition}

This study regards the Web of Science Core Collection as a data-collection platform according to data resources required in CiteSpace. The bibliometric search strategy can be described as the following: Topics $=$ ("ecological health" or "ecosystem health"), time span $=1989-2018$, and language $=$ English [18]. We ultimately selected 3886 documents by removing irrelevant documents and merging synonyms $[14,16]$. Regarding the time period of the retrieved data, we mainly considered that time range for two reasons. First, the concept of ecosystem health was officially proposed in the late 1980s. Schaeffer et al., (1988) explored the definition of ecosystem health and suggested criteria that can support assessments of ecosystem status [19]. However, Rapport (1989) also considered the sustainability of ecosystems on the basis of some relevant criteria [20]. Besides, few publications can be found and there are none available from an earlier time.

\subsection{CiteSpace}

CiteSpace, the Java application, can be used to generate knowledge-domain visualization [21]. It addressed some issues compared to earlier visualization tools; for instance, improving clarity and network transitions [22]. It can be used to search for landmark, hub, and pivot nodes, and detect and track the evolution of a research domain [23]. CiteSpace has a clear interface setting and is user-friendly [16]. Specifically, settings mainly include nodes, time slicing, thresholding, modeling, pruning, merging, and mapping [22]. CiteSpace has 3 core concepts: burst detection, betweenness centrality, and heterogeneous networks. These concepts can solve 3 practical problems: identifying the nature of research frontiers, marking keywords, and identifying emerging trends and sudden changes in time [23,24]. After the visualization of input data through CiteSpace, we can illustrate the intellectual structure and internal relationship of the ecological-health domain [25]. Nodes and links are the building blocks in visualization mapping. Nodes represent analysis objects (e.g., categories, cited authors, cited journals, cited references, and keywords) and links describe the inter-relationship between these nodes. Each node is a combination of concentric circles in different colors. Nodes with a purple ring indicate they have high centrality and can be recognized as pivotal points. In addition, CiteSpace can execute burst detection so that nodes with a high-frequency change rates are shown with red rings. Based on burstiness, we can identify interest in a specialty and reach research frontiers [14].

\subsection{Co-Citation Analysis}

Co-citation refers to the frequency with which two earlier items of the literature are cited together by the later literature [24]. It can elaborate the relationship between different analysis objects, such as cited authors, journals, and references. Then, an intellectual scientific structure of co-citation patterns viewed over a period of time is indicative of the mechanism of specialty development [21]. Moreover, co-citation could give us important insights into the knowledge domain that conventional citation analysis overlooks [26]. In this study, we apply co-citation analysis methods like author, journal, and document co-citation to find influential authors, popular journals, key studies, and major research areas in the knowledge domain. For the co-citation analysis instance mentioned above, we set a time span from 1989 to 2018 and selected the top 50 most cited items in each time slice to analyze their intellectual structure and the dynamics of co-citation clusters. It should be noted that different item-citation frequency (e.g., cited authors, journals, and studies) reflects, to some extent, their different influential force regarding the research area [14]. Among these analyses, document co-citation analyses can generate results of co-citation clusters, landmark references, and references with citation bursts. In order to characterize the nature of a cluster, CiteSpace can extract noun phrases from the titles of articles that cited the clusters based on specialized metrics: log-likelihood tests (LLR), which usually give the best results in terms of the uniqueness and coverage of themes associated with a cluster [27]. CiteSpace can also calculate the values of modularity $Q$ and mean silhouette according to the overall 
structural properties of the network. Modularity $Q$ describes clusters' divisional quality, and the value is $0-1$. If the value is above 0.3 , the network structure could be considered significant [28]. A mean silhouette is an index to measure the homogeneity of a cluster, ranging from -1 to 1 ; the greater the value is, the higher the similarity between cluster members is. The average year of publication of a cluster indicates its recentness. Blue areas were generated earlier than green areas, yellow areas were generated after green areas, and so on.

\subsection{Keyword Co-Occurrence Analysis}

Keywords are the essence of the literature content and subject; that is, the core content. Thus, keyword co-occurrence analysis is an effective way to detect the hot topics and evolving research frontiers of particular research fields over time. The evolution of research topics has always been a research issue that researchers have been concerned about because it helps researchers to understand the development of certain areas, pioneer in that area, and finally determine corresponding research directions. In this paper, we set a time span from 1989 to 2018, selected the top 50\% most occurring items in each time slice to monitor hot topics and development trends in ecosystem health field, and established future research directions.

\section{Results}

\subsection{Annual Variations of Publications and Their Categories}

The annual numbers of publications during 1989-2018 are shown in Figure 1. According to the figure, we can form a preliminary understanding concerning ecological-health research after annual analysis. In one respect, increasing annual literature numbers reflect the development speed of the research area. In another respect, the phenomenon of literature numbers increasing year by year fully explains studies on ecological health increasing. On the whole, literature numbers on ecological health have been steadily growing and can be split into three parts.

(1) Initial phase (1989-1996). Published papers prior to 1996 for each year were below 40, and increased in frequency slowly. The formation of the First International Workshop on Ecosystem Health and the International Society for Ecosystem Health (ISEH), followed by the publication of the first graduate textbook on ecosystem health, made scholars begin to pay attention to the concept and the importance of ecosystem health, and conduct relevant research.

(2) Development phase (1996-2006). The annual number of published papers increased gradually and fluctuated until 2006. The reason might be related to influential international conferences, symposium, and publications, such as the First Eco-summit, co-convened by D. Rapport and S. E. Jorgensen, the Indo-Pacific Conference on Ecosystem Health, sponsored by Edith Cowan University, and the publication of Managing for Healthy Ecosystems.

(3) Rapid-development phase (2006-2018). Correspondingly, published papers for each year have been increasing rapidly after 2006. This might be relevant to the background of environmental stress and deterioration, resulting from populations' increasing and growing economies, along with EcoHealth Conferences sponsored by scholars focused on the intersection of health and ecology [1]. Achieving a condition that can reflect a healthy ecosystem is an ongoing global priority for governments, scientists, and managers [29]. Following this, scholars have been paying increasing attention to this research area. 


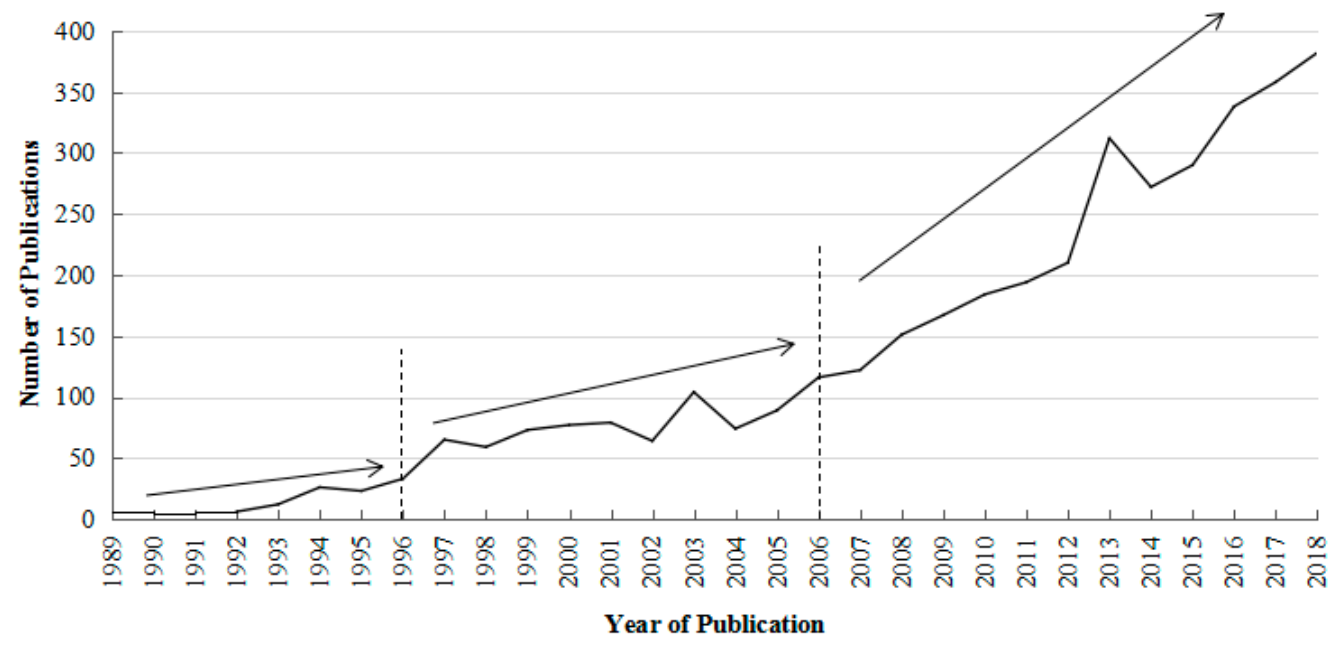

Figure 1. Annual variations of publications on ecosystem health in the Web of Science.

Publications on ecosystem health covered various subject categories in the Web of Science. In order to understand the distributions of subject categories and the dominant categories, we conducted co-occurring category analysis to help us identify disciplines in the development process of the research area [30]. In this paper, we set a time span from 1989 to 2018 and selected the top 30\% most occurring subject categories per time slice to analyze the categories' development characteristics. Figure 2 shows the simplified co-occurrence network of subjects with high frequency in the ecosystem health domain, and Figure 3 shows the top 10 most frequently appearing subject categories with frequency and centrality. The study results revealed the significance of subjects involved in ecological-health research.

(1) Environmental sciences \& ecology, the largest node with a frequency of 2241 (Figure 3), is the most popular subject category, followed by environmental sciences (1768), ecology (844), marine \& freshwater biology (556), and water resources (460), which signifies scholars in the field are most concerned about the environmental, ecological, and water-resource aspects.

(2) Among the top 10 most frequently appearing subject categories, environmental sciences has the highest centrality, which means environmental sciences plays an important pivotal role in ecological health and it is the key connection hub in communicating different subjects in the area. Ecology comes second, followed by engineering, and environmental sciences \& ecology. Thus, environmental sciences, ecology, and engineering have an intermediary role, and play a critical role in the research of the network structure.

(3) According to the circles' colors, we can judge the age of the research subjects. As we can see, the earliest studies on ecological health were mainly in environmental sciences \& ecology, and environmental sciences, which have blue inner circles. In addition, relatively new areas, such as marine and freshwater biology, and engineering, have yellow inner circles. Thus, ecological-health research is multifaceted and covers quite a wide range of interests, from environmental science and water, to engineering, biodiversity, and toxicology. 


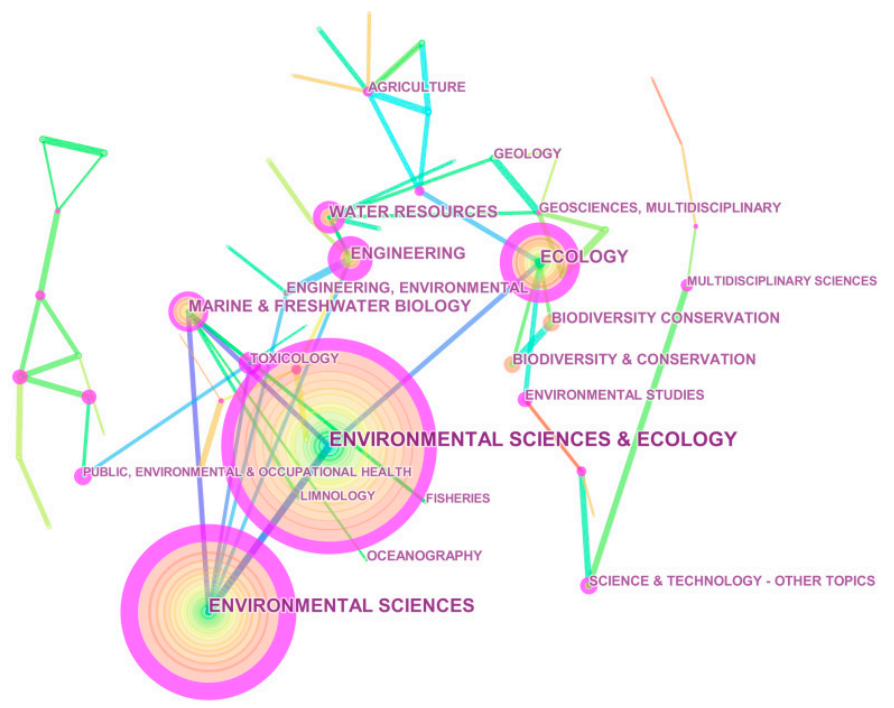

Figure 2. Top 20 categories during 1989-2018.

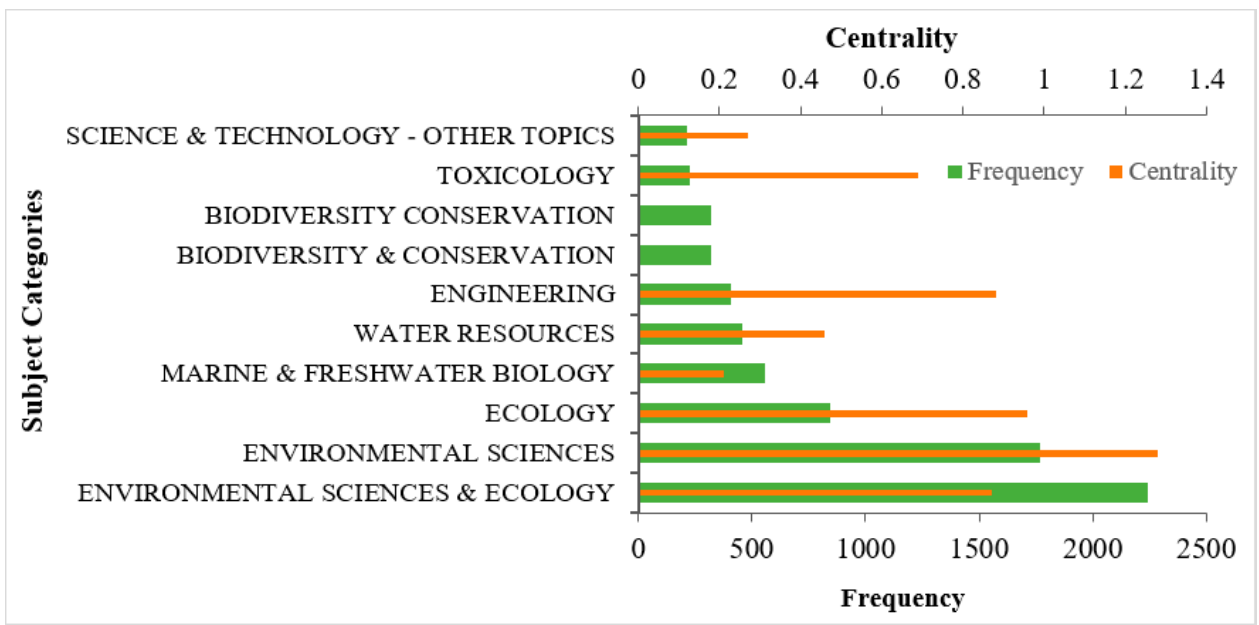

Figure 3. Top 10 most frequently appearing subjects with frequency and centrality.

\subsection{Co-Citation Analysis of Ecosystem Health Research}

\subsubsection{Author Co-Citation Analysis}

In order to detect influential authors in the research area, the top 10 most cited authors in the ecosystem health area are listed in Table 1. It can be seen that Rapport, D.J., ranks first, with 354 citations, followed by Costanza, R., with 321 citations. They are the most representative figures who acted as pioneers to explore the definition of ecosystem health and the relative integral index system [3,31]. Other highly cited authors included Karr, J.R. (302), Clarke, K.R. (126), Barbour, M.T. (124), and Poff, N.L. (123). Moreover, we can track highly cited authors, thus influential researchers in relevant research domains, to find hot topics and research frontiers.

Table 1. Top 10 frequently cited authors in the ecological-health area.

\begin{tabular}{cccccc}
\hline$\#$ & Author & Frequency & $\#$ & Author & Frequency \\
\hline 1 & Rapport, D.J. & 354 & 6 & Poff, N.L. & 123 \\
2 & Costanza, R. & 321 & 7 & Vitousek, P.M. & 121 \\
3 & Karr, J.R. & 302 & 8 & Bunn, S.E. & 117 \\
4 & Clarke, K.R. & 126 & 9 & Jorgensen, S.E. & 103 \\
5 & Barbour, M.T. & 124 & 10 & Cairns, J. & 99 \\
\hline
\end{tabular}




\subsubsection{Journal Co-Citation Analysis}

This section shows the journals in the ecosystem health domain between 1989 and 2018. The journal co-citation network is shown in Figure 4, and Table 2 illustrates the 10 most popular journals in the field of ecological health (1989 to 2018) by total number of citations. As shown in Table 2, the top ranked item by citation counts was Science, with 1265 , followed by Nature. On the grounds of the results, it was not difficult to determine that these two journals were the main sources of cited work for ecological-health researchers. These two top academic journals also had higher Impact Factors (41.058 and 41.577), and published original articles across an extensive range of scientific fields, which indicates that the two journals have stronger influence on the related research. Figure 4 depicts the simplified network of the most cited journals. It can be seen that some nodes have purple rings around the outer rim that indicates a tight connection with other journals. That is to say, Science, Nature, Ecological Applications, Environmental Science and Technology, Ecology, Bioscience, and Environmental Management are core nodes and have a good interrelationship with other journals of ecosystem research. Moreover, ecological health research covers an extensive range of topics, from science, nature, and the environment to hydrobiologia, bioscience, and management.

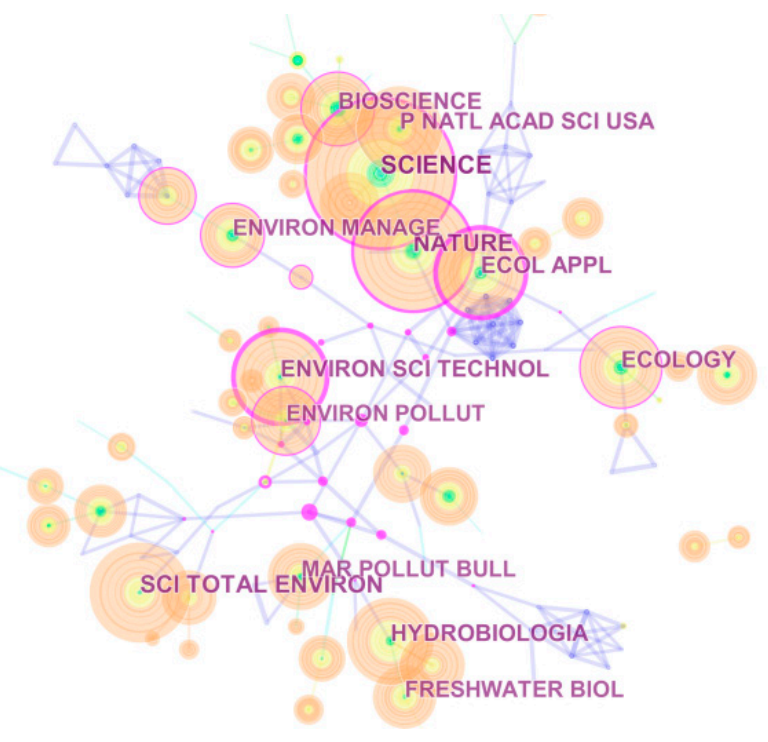

Figure 4. Top 10 frequently cited journals and their network.

Table 2. Top 10 journals according to frequency in ecological health.

\begin{tabular}{ccccc}
\hline$\#$ & Frequency & Centrality & Journals & IF 2017 \\
\hline 1 & 1265 & 0.26 & SCIENCE & 41.058 \\
2 & 1037 & 0.29 & NATURE & 41.577 \\
3 & 872 & 0 & SCIENCE OF THE TOTAL & 4.61 \\
4 & 828 & 0.07 & ENVIRONMENT & 2.165 \\
5 & 822 & 0.43 & HYDROBIOLOGIA & 4.393 \\
6 & 816 & 0.42 & ENVIRONMENTAL SCIENCE and & 6.653 \\
& & & TECHNOLOGY & \\
7 & 733 & 0 & ACADEMY OF SCIENCES OF THE & 9.504 \\
8 & 732 & UNITED STATES OF AMERICA & 4.617 \\
9 & 698 & ECCOLOGY & 5.876 \\
10 & 644 & 0.13 & BIOSCIENCE & 2.177 \\
& & 0.15 & ENVIRONMENTAL \\
\hline
\end{tabular}




\subsubsection{Cluster Analysis}

With the purpose of knowing representative reference clusters, we constructed a document co-citation network containing 3886 references during 1989 to 2018. In the synthesized network, the modularity $Q$ that we generated reached 0.8876 , so we concluded that the cluster results were significant, whereas the mean silhouette score of 0.238 was relatively low, mainly because of the numerous small clusters. In terms of silhouette values, the major clusters that we focus on are sufficiently high. In other words, grouping quality is high.

As shown in Figure 5, there are 10 key co-citation clusters in the network and these clusters are labeled by index terms; detailed information of the 10 clusters is summarized in Table 3. The earliest structure consists of some of the largest clusters; examples: \#0, labeled a natural resource value; \#2, labeled cross-sectional study; \#3, labeled large marine ecosystems; \#6, labeled inventory; \#7, labeled condition; and \#8, labeled Lake Chao. The midterm structure primarily includes \#1, labeled cellulose-decomposition potential, and \#5, labeled urban-ecosystem health. The most recent structure consists of \#4, labeled water quality, and \#9, labeled wetland.

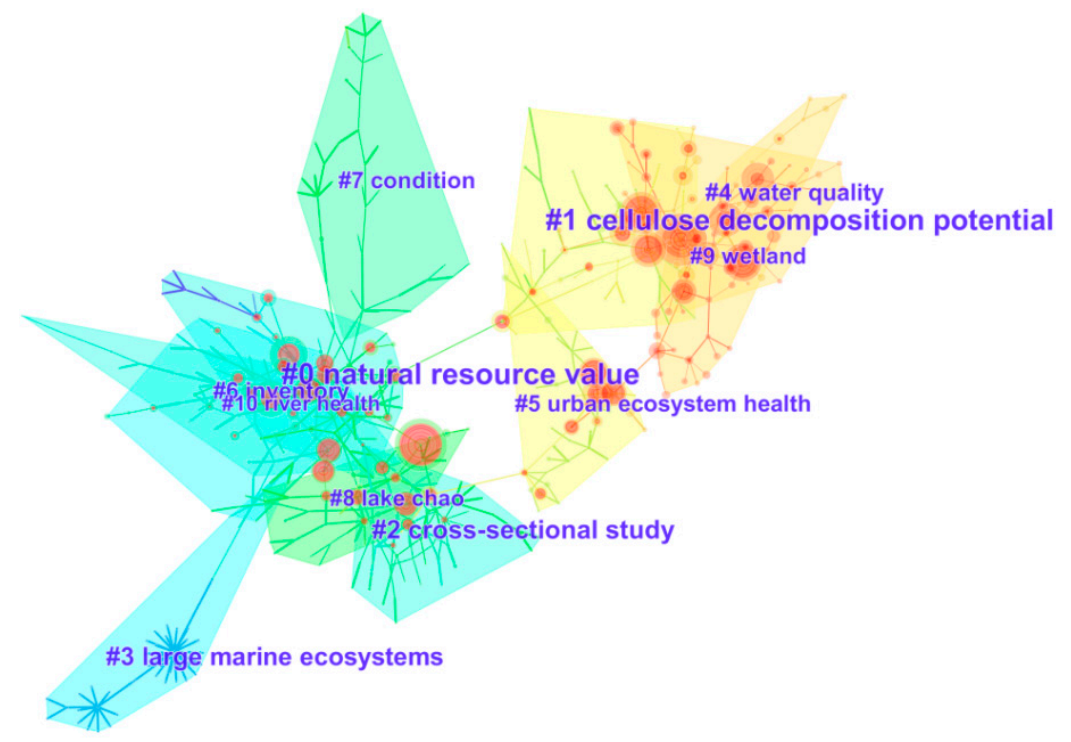

Figure 5. Cluster visualization based on the document co-citation network of 1989-2018.

Table 3. Top 10 key co-citation clusters based on frequency in ecological health.

\begin{tabular}{ccccc}
\hline Cluster ID & Size & Silhouette & Label (LLR) & Mean (Cite Year) \\
\hline 0 & 63 & 0.828 & natural resource value & 1994 \\
1 & 62 & 0.916 & cellulose decomposition potential & 2006 \\
2 & 49 & 0.945 & cross-sectional study & 1997 \\
3 & 46 & 0.987 & large marine ecosystems & 1990 \\
4 & 40 & 0.915 & water quality & 2012 \\
5 & 39 & 0.990 & urban ecosystem health & 2006 \\
6 & 39 & 0.941 & inventory & 1993 \\
7 & 38 & 0.965 & condition & 1998 \\
8 & 37 & 0.915 & lake chao & 1999 \\
9 & 36 & 0.862 & wetland & 2011 \\
\hline
\end{tabular}

Cluster \#0, the largest cluster, had 63 members and a silhouette value of 0.828 . It was labeled natural resource value. Through analysis, we found this cluster mainly focused on the concept of the measurements of ecosystem health and the development of an ecosystem health indicator framework [5,32-34]. The most active citer in this cluster was "Ecosystem Health: The Concept, the ISEH, and the Important Tasks Ahead." The third largest cluster (\#2), labeled cross-sectional study, had 
49 members and a silhouette value of 0.945 . The cluster had the same active citer as Cluster \#0. This cluster highlighted the integration of the complex social and biophysical processes that characterize human and ecosystem health [35]. In addition, this cluster included environmental and ecological health assessments related to advanced technology, such as the application of remote sensing [36]. Cluster \#3 had 46 members and a silhouette value of 0.987 . It was labeled large marine ecosystems. This cluster concentrated on the monitoring and management of coastal ecosystem health, especially large marine ecosystems $[37,38]$. The most active citer to the cluster was "Sustainability, biomass yield, and health of coastal ecosystems: an ecological perspective." Cluster \#6, labeled inventory, had 39 members and a silhouette value of 0.941 . This cluster mainly illustrated the need for a comprehensive and multiscale concept of ecosystem health, and addressed the measurement of various ecosystems (for example, those of rivers, forests, estuaries, and freshwater) $[32,33,39,40]$. The most active citer to the cluster was "Defining and measuring river health." Cluster \#8, labeled Lake Chao, had 37 members and a silhouette value of 0.915 . This cluster mainly involved a lake ecosystem health assessment based on indicators and models [41-46]. The most active citer to this cluster was "A method for lake ecosystem health assessment: an ecological modeling method and its application." In addition, Cluster \#0 had the top ranked centrality article, entitled "Defining and measuring river health," with a centrality of 0.28. This article effectively connected the earliest cluster structure to the midterm cluster structure.

Cluster \#1, the second largest cluster, had 62 members and a silhouette value of 0.916 . It was labeled cellulose decomposition potential. This cluster was mainly related to the measurement of functional ecosystem variables, such as ecosystem metabolism and the rates of organic-matter processing [47-51]. The most active citer to this cluster was "Exploring the response of functional indicators of stream health to land-use gradients." Cluster \#5, labeled urban-ecosystem health, had 39 members and a silhouette value of 0.990 . This cluster paid more attention to ecological system modeling and the evaluation of urban ecosystems [52-55]. The most active citer to this cluster was "Relative urban ecosystem health assessment: A method integrating comprehensive evaluation and detailed analysis." In addition, Cluster \#1 had the second most ranked centrality article, entitled "Global threats to human water security and river biodiversity," with a centrality of 0.25 . This article effectively connected the midterm cluster structure to the midterm cluster structure.

Cluster \#4, labeled water quality, the most recently formed cluster, had 40 members and a silhouette value of 0.915 , and contained numerous nodes with red rings of citation bursts. This cluster mainly involved the assessment and management of river health, which means water quality, especially river water quality, which is a research direction on which scholars are focusing [56-61]. The most active citer to this cluster was "How good are Bayesian belief networks for environmental management? A test with data from an agricultural river catchment." Cluster \#9, labeled wetland, is also a relatively new cluster. This cluster mostly illustrated health indices, integrated modeling, and the assessment and management of wetlands, including rivers and coastal wetlands [62-68]. This means that wetlands, a subject that has attracted scholarly attention, have the possibility to become a hot spot for this research area. The two clusters mentioned above both emphasize wetland assessment and management, especially river ecosystems, hence the modeling and assessment of river ecosystems have been hot topics since 2010. The most active citer to this cluster was "Integrated modelling of cost-effective siting and operation of flow-control infrastructure for river ecosystem conservation."

In summary, the research area of ecological health included many aspects, such as concept exploration, the establishment of ecological health indicators and models, ecological integration, cellulose decomposition potential, urban ecosystem health assessment, and wetland ecosystem health assessment and management. In the early period, scholars mainly focused on the conceptualization and measurement of ecosystems' health based on investigation indicators, and began to emphasize the necessity of ecosystem health assessments. In the mid period, with the economy developing, scholars began to turn their focus on urban ecosystem health assessments. In addition, scholars emphasized functional indicators relevant to ecosystems and eventually provided a framework to assess ecosystems' health. In the recent period, researchers have been paying more attention to various wetland ecosystem 
health evaluations, and its conservation. As a result, newly identified trends appear to focus on the assessment and management of wetland ecosystems.

\subsubsection{Landmark References}

Based on document co-citation analysis, we could easily identify the key literature in the relevant area. Table 4 lists the top 10 highly cited references in ecological health based on co-citation network analysis. It should be noted that the listed references were not the most cited items from Web of Science and Google Scholar, but the most cited from the 3886 studies obtained in this paper.

Table 4. Top 10 highly cited references based on frequency in ecological health.

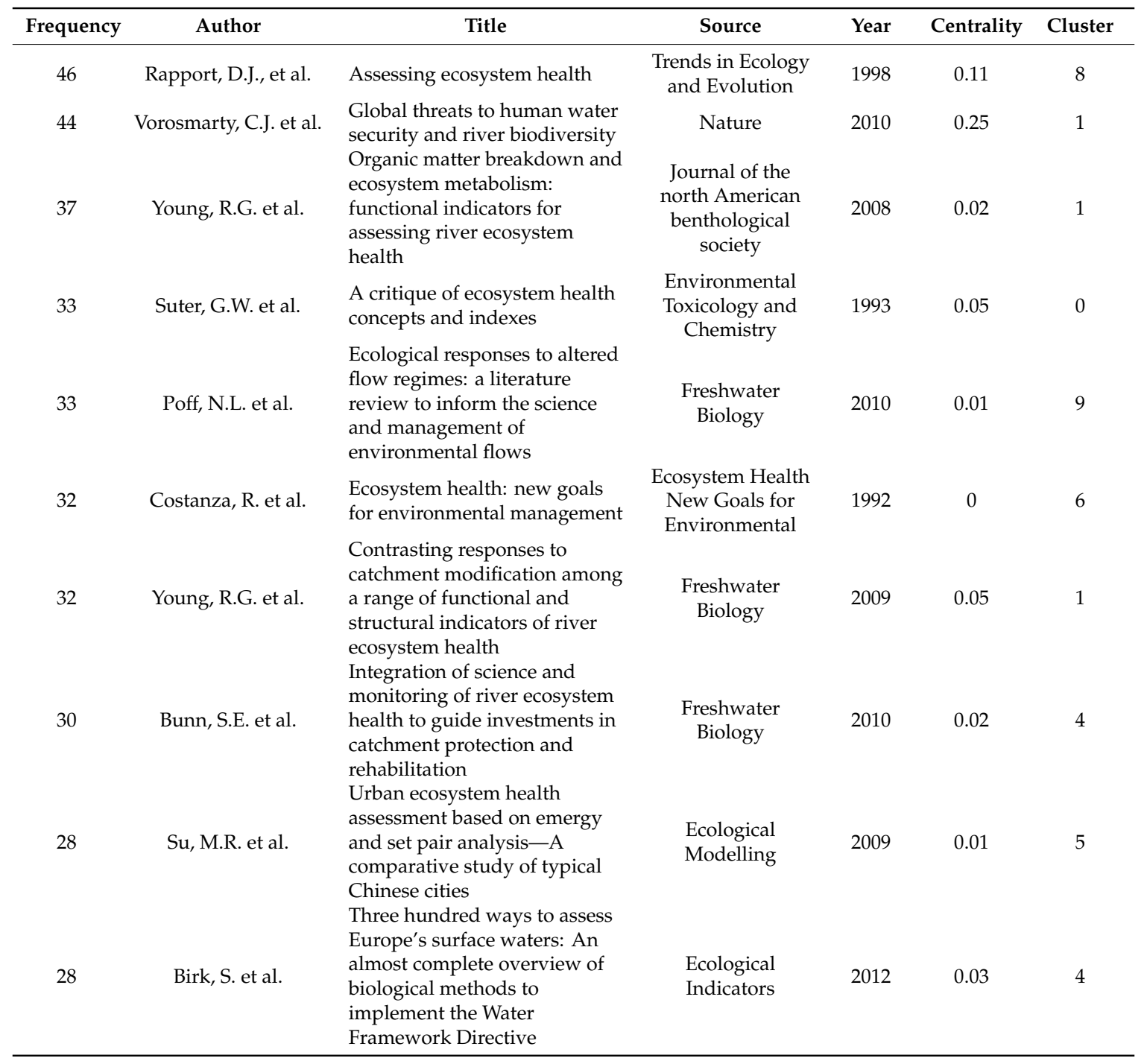

From the top 10 cited references, two are associated with the concept, three are related to functional and structure indicators, two are relevant to ecosystem health assessments, and three are about freshwater-framework development. Obviously, Rapport, D.J. et al., (1998) [69] was the most frequently cited; frequency was 46 . The paper outlined the necessity for assessing ecosystem health and presented the integration of ecological, social, and health science. Vorosmarty, C.J. et al., (2010) [70] ranked second with a frequency of 44. The paper first reported global freshwater threats, and selected rivers, a major source of human water supply and freshwater ecosystems, to analyze human water security and biodiversity for the first time. Young, R.G. et al., (2008) [71] ranked third, with a frequency of 37. The paper discussed factors that affect leaf breakdown and river metabolism, 
especially human factors, considered the advantages and disadvantages of both methods as functional measures, and eventually provided a framework to assess river ecosystem health. Suter, G.W. et al., (1993) [72] ranked fourth with a frequency of 33. The paper elaborately critiqued the concepts and indices of ecosystem health, evaluated the suitability of methods that are applied to implement the concept, and ultimately discussed alternative regulatory and management goals. Poff, N.L. et al., (2010) [73] ranked fifth with a frequency of 33. The paper reviewed 165 papers published in the past 40 years to determine the general relationship between flow alteration and ecological responses, and concluded that the majority of papers reported decreased values for recorded metrics in response to various flow alterations, whereas only a minority of papers reported increased values. Moreover, this paper provided quantitative analysis of the ecological response to flow alteration based on the existing global literature, and confirmed the association between flow alteration and ecological change. Costanza, R. et al., (1992) [74] ranked sixth, with a frequency of 32. The paper comprehensively gave a definition of ecosystem health by synthesizing past representative definitions at all scales and eventually proposing a general index composed of vigor, organization, and resilience, which can be put into practice, and is helpful for environmental management. Young, R.G. et al., (2009) [75] ranked seventh with a frequency of 32. The paper measured the responses of ecosystem metabolism, organic-matter decomposition, and invertebrate-community composition across a catchment-impairment gradient. The study explored if there were consistent responses to an impairment gradient among contrasting functional indicators of river ecosystem health, and the relationship between structural and functional indicators. Bunn, S.E. et al., (2010) [50] ranked eighth with a frequency of 30. The paper described the development of a freshwater ecosystem health monitoring program using concept models and potential indicators against a known disturbance gradient, and how this has been used to report on stream-ecosystem health on a regional scale. The paper also explored emerging science needs to identify the appropriate scale and spatial arrangement of riparian protection and rehabilitation, which can maximize river ecosystem health outcomes and derive other downstream benefits at the same time. Su, M.R. et al., (2009) [76] ranked ninth with a frequency of 28. The paper described the development framework of energy based urban ecosystem health indicators, composed of vigor, structure, resilience, ecosystem service function maintenance, and environmental impact, and used this framework to assess urban ecosystem health. The paper also evaluated and compared urban ecosystem health levels in 20 typical Chinese cities based on urban ecosystem health indicators and set pair analysis. Birk, S. et al., (2012) [77] ranked last in the list with a frequency of 28. The paper first provided a relative overall review of bioassessment methods for European aquatic ecosystems to implement the Water Framework Directive. Moreover, the paper explored similarities and differences among the series of methods, and focused on the implementation of scientific concepts and standards of aquatic bioassessment.

\subsection{Emerging Ecosystem Health Trends}

\subsubsection{References with Citation Bursts}

Through the co-citation literature burst dictation, we found that there are many articles with citation bursts, and we selected the top 10 articles with a burst, beginning after 2012, as shown in Table 5 , to analyze emerging trends. From 2012 to 2018, researchers primarily focused on: human water security and the bioassessment of aquatic ecosystems [70,77,78]; the development of an ocean-health index and a spatial model for marine ecosystems on a global scale $[79,80]$; the association between flow alteration and ecological change [73]; ecosystem-service value estimates and ecological engineering [81,82]; the implementation of the Water Framework Directive (WFD); and the measurement of the effects of nutrient pollution on stream-ecosystem functioning $[83,84]$. Therefore, health assessment, driver analysis, and the ecological restoration of coastal and river ecosystems being closely related to human well-being are future research directions. Ecological engineering based on the concepts of ecosystem health, ecosystem services, and sustainability can and must play a significant role in that evolution. 
Table 5. Top 10 articles with bursts beginning after 2012 in ecological health.

\begin{tabular}{cccccc}
\hline References & Year & Strength & Begin & End & 1989-2018 \\
\hline Vorosmarty, C.J. et al. & 2010 & 17.77 & 2012 & 2018 & \\
Birk, S. et al. & 2012 & 14.57 & 2015 & 2018 & \\
Poff, N.L. et al. & 2010 & 12.58 & 2012 & 2018 & \\
Halpern, B.S. et al. & 2012 & 10.08 & 2013 & 2018 & \\
Poff, N.L. et al. & 2010 & 9.82 & 2012 & 2016 & \\
Halpern, B.S. et al. & 2008 & 9.26 & 2013 & 2016 & \\
Costanza, R. et al. & 2012 & 7.77 & 2015 & 2018 & \\
Hering, D. et al. & 2010 & 7.25 & 2015 & 2018 & \\
Costanza, R. et al. & 2014 & 6.73 & 2015 & 2018 & \\
Woodward, G. et al. & 2012 & 6.16 & 2013 & 2016 & \\
\hline
\end{tabular}

\subsubsection{Keyword Co-Occurrence Analysis}

Table 6 lists keywords with stronger citation bursts in different periods, and research topics and changes in the research area of ecological health are presented. As we can see, Table 6 shows the first time that each keyword appeared, and its duration, which reflects the length of keyword's influence in the research area. Moreover, what should be noted is that the line illustrated by blue in the table means the whole study period (1989-2018), and the red line represents the duration of the citation burst [13]. In addition, in order to more exactly detect the research topics in ecological health and master their development rules from 1989 to 2018, we divided the development period into three parts. The main topics of different periods can be summarized as concept exploration and the framework development of ecosystem health, monitoring ecological indicators and ecosystem health assessments, and the assessment and management of aquatic ecosystems.

Table 6. Keywords with stronger citation bursts in different periods.

\begin{tabular}{|c|c|c|c|c|c|}
\hline Period & Keyword & Burst & Begin & End & 1989-2018 \\
\hline \multirow{5}{*}{ 1989-1999 } & ecosystem health & 32.71 & 1993 & 2004 & \\
\hline & stress & 11.97 & 1993 & 2002 & \\
\hline & ecology & 9.54 & 1996 & 2004 & \\
\hline & integrity & 11.20 & 1997 & 2004 & \\
\hline & ecosystem management & 7.68 & 1998 & 2001 & \\
\hline \multirow{8}{*}{ 2000-2010 } & ecological indicator & 6.41 & 2000 & 2007 & \\
\hline & ecotoxicology & 4.75 & 2002 & 2008 & \\
\hline & risk & 5.23 & 2003 & 2009 & \\
\hline & sustainable development & 4.76 & 2004 & 2009 & \\
\hline & bioassessment & 8.93 & 2006 & 2010 & \\
\hline & forest & 5.44 & 2008 & 2011 & \\
\hline & set pair analysis & 8.20 & 2009 & 2012 & \\
\hline & ecosystem health assessment & 5.91 & 2010 & 2013 & \\
\hline \multirow{6}{*}{ 2011-2018 } & surface water & 8.33 & 2013 & 2018 & \\
\hline & river basin & 5.72 & 2014 & 2018 & \\
\hline & oxidative stress & 7.04 & 2014 & 2018 & \\
\hline & waste water & 8.11 & 2016 & 2018 & \\
\hline & ecological restoration & 4.26 & 2016 & 2018 & \\
\hline & aquatic ecosystem & 4.24 & 2016 & 2018 & \\
\hline
\end{tabular}

(1) Concept Exploration and Framework Development of Ecosystem Health

As is shown, most of the keywords in the period of 1989 to 1999, such as "ecosystem health" (32.71), "stress" (11.97), "ecology" (9.54), and "integrity" (11.20) had a longer burst duration than the keywords in the second and the third research periods. It is safe to assume that studies related to these keywords can be regarded as research pioneers in the domain of ecological health. They can serve as important 
and fundamental sources for ecological-health development and new research branches. The First International Symposium on Ecosystem Health and Medicine brought the concept of ecosystem health to the attention of the international scientific community [1]. It addressed the topic of environmental and population challenges, and it also explored the interfaces between various disciplines involved. Human activities have put pressure on ecosystems and affected them in different ways, such as biotic impoverishment $[85,86]$. Concerns about the problems, and the concept of ecological health or ecological integrity are regarded as guiding policy-making principles [87]. Scholars have also paid more attention to the framework for ecosystem assessment and management of human activities to preserve ecosystem health $[88,89]$.

(2) Monitoring Ecological Indicators and Ecosystem Health Assessment

During the period of 2000-2009, "ecological indicator" (6.41), "risk" (5.23), "sustainable development" (4.76), "bioassessment" (8.93), and "set pair analysis" (8.20) were hot topics for scholars. Human activities reduced the ecological integrity of natural ecosystems, including ecosystem structure and processes. In the initial stage, land-use-impact bioassessments mainly focused on structural metrics, and river ecosystem bioassessments accounted for a large proportion [90,91]. However, few methods were used to detect stressor impacts that altered ecosystem processes [92,93]. Environmental changes resulting from human activities consequently damaged sustainability, and impaired ecological functions and societal services [47-49], which provided the grounds for addressing ecosystem health in a holistic way. Gradually, the functional measurement of stream-ecosystem health was addressed and became a hot topic during this period. Cities, dense population centers, are inevitably affected by human activities. In order to understand the health status of urban ecosystems, a relevant framework of urban ecosystem health was proposed, and fulfilled by energy synthesis and set-pair analysis [52,55].

\section{(3) Assessment and Management of Aquatic Ecosystems}

Furthermore, keywords in the period of 2010 to 2018, such as "surface water" (8.33), "river basin," "oxidative stress" (7.04), "waste water" (8.11), "ecological restoration" (4.26), and "aquatic ecosystem" (4.24) could represent new topics, even the major frontier of ecological health research, because their burst duration has lasted until the present. In recent years, ecological integrity, biodiversity, and water quality in aquatic ecosystems have been declining on a global scale $[94,95]$. The phenomenon can be explained by various interacting stressors [73,96], such as eutrophication [97], agricultural needs [73,98], and changing regimes [99]. Pollution decreased ecosystem services and finally caused ecosystem degradation $[64,100]$. Facing the degradation of aquatic ecosystems by numerous sources of anthropogenic pressure, necessary ecological restoration after ecological diagnosis and management has attracted researchers' attention [101].

\section{Discussion and Conclusions}

Ecosystem health is a comprehensive concept integrating biophysical, human and social-economic aspects. As an interdisciplinary research, it is of great significance for various fields, from ecology and public health, to environmental management, and ecological economics. Meanwhile, it is vital and urgent to form a comprehensive understanding of this research. In the present work, we used CiteSpace to analyze the research status and evolving trends from a macroscopic view to a microcosmic view; from whole to parts.

First, publications on ecosystem health indicate a strong increase from 1989 to 2018, especially after 2006. The study has multidisciplinary research involved in various subject categories. Rapport, D.J. and Costanza, R. are the most representative figures who acted as pioneers to explore the definition of ecosystem health and the relative integral index system. By tracking these influential researchers in the relevant research domain, we more easily find hot topics and research frontiers. Second, three major research areas were identified over the decades. The first focuses on concept exploration 
and framework development of ecosystem health, which lays the foundation for ecosystem health research; the second emphasizes monitoring ecological indicators and ecosystem health assessment; the third concentrates on the assessment and management of aquatic ecosystems. Between them, monitoring ecological indicators and ecosystem health assessments are the most active area throughout all ecosystem health studies. Thus, this area can be considered to represent the critical transition in the history of the development of the field. The assessment and management of aquatic ecosystems is the area that has most attracted scholars' attention in recent years. Additionally, necessary ecological restoration after ecological diagnoses and management has also attracted the scholars' attentions.

Through analysis, we inferred that the following areas have the possibility to become hot topics in the future. Further progress in the way ecosystem assessments are approached may continue to rise, as molecular techniques and new types of biodiversity indicators are developed [101,102]. Therefore, from a microcosmic view, using the indicators generated by molecular techniques to conduct wetland-ecosystem assessments is likely to become a popular area in the ecosystem health field. This is consistent with other studies, but previous studies are limited only to the freshwater domain [7]. Relevant studies have reviewed remote-sensing opportunities to develop a comprehensive ecosystem health system [8]. Thus, from a macroscopic view, assessing the health status of aquatic ecosystems using advanced technology (Geographical Information System and remote sensing) on a large scale could also become future research topics. Aquatic ecosystems are closely related to human life, so ecological-restoration engineering of aquatic ecosystems has the potential to develop as a research hot topic in the future. Compared to previous reviewed articles, our study is consistent, and our study is more comprehensive and timely.

This study is of great significance and can be summarized as follows. This study can present the overall picture of ecosystem health development, and development pathways which are helpful for scholars to reach research frontiers and determine future directions. Furthermore, this study presents an overall picture of the development of ecosystem health, and has important referencing implications for policy making and academic research. That is to say, the results we generated above contribute to actual policy-making processes. This is helpful in optimizing the internal tradeoffs between resource exploitation and conservation. However, there are some limitations to our paper. On the one hand, we collected the literature data from the WOS Core Collection as study objects, and though crucial, the Web of Science database did not provide all publications available, especially publications in non-English-speaking countries. Compared to a bibliographic database, Web of Science is a database that includes a comprehensive number of studies. Thus, the results we analyzed in this paper are persuasive and can represent the hot topics, evolving trends, and research frontiers of the ecosystem health domain. On the other hand, CiteSpace has data-format requirements that result in little deviations that were unavoidable in our study. The results of this study are based on objective data analysis that is hardly influenced by subjective experience, thus making them stable and objective [14].

In conclusion, through scientometric methods, we identified Rapport, D.J. and Costanza, R. as the representative figures, who greatly contributed to the definition of ecosystem health in the early period. Besides that, we gave some landmark references in the history of ecosystem health development. Our analysis revealed that ecosystem health research mainly included three aspects: concept exploration, ecological indicators' monitoring, and the management of aquatic ecosystems. Analysis suggested that management and restoration of aquatic ecosystems is the hot topic in recent years. Assessing the health status of aquatic ecosystems from a microcosmic view and macroscopic view, along with the responding ecological-restoration engineering, will be the focuses of future research. On the whole, this study can help scholars to efficiently identify the most significant and influential trends occurring in the area of ecosystem health. The study results could also assist ecological and environmental researchers to explore critical research that can provide ideas for some fundamental studies and new issues, and guide scholars to build new perspectives. Furthermore, the results we generated above 
can contribute to actual policy-making processes. This is helpful in optimizing the internal trade-offs between resource exploitation and conservation.

Author Contributions: H.Y., X.S., and M.W. designed the study; H.Y. and X.S. performed the research and analyzed the data; H.Y. wrote the first draft of the manuscript; and all authors contributed to revisions and gave their approval for publication.

Funding: This study was supported by the National Natural Science Foundation of China (31870597), the special fund for cooperation of Zhejiang Province and Chinese Academy of Forestry (2018SY03) and the Zhejiang Provincial Natural Science Foundation of China (LY18D010005).

Conflicts of Interest: The authors declare that they have no conflict of interest.

\section{References}

1. Rapport, D.J.; Maffi, L. Eco-cultural health, global health, and sustainability. Ecol. Res. 2011, 26, 1039-1049. [CrossRef]

2. Schuler, M.S.; Cañedo-Argüelles, M.; Hintz, W.D.; Dyack, B.; Birk, S.; Relyea, R.A. Regulations are needed to protect freshwater ecosystems from salinization. Philos. Trans. R. Soc. B 2018, 374, 20180019. [CrossRef]

3. Costanza, R. Toward an operational definition of ecosystem health. Ecosyst. Health New Goals Environ. Manag. 1992, 239, 269.

4. Mageau, M.T. The development and initial testing of a quantitative assessment of ecosystem health. Ecosyst. Health 1995, 1, 201-213.

5. Rapport, D.; Böhm, G.; Buckingham, D.; Cairns, J.; Costanza, R.; Karr, J.; De Kruijf, H.; Levins, R.; McMichael, A.; Nielsen, N. Ecosystem health: The concept, the ISEH, and the important tasks ahead. Ecosyst. Health 1999, 5, 82-90. [CrossRef]

6. Tett, P.; Gowen, R.; Painting, S.; Elliott, M.; Forster, R.; Mills, D.; Bresnan, E.; Capuzzo, E.; Fernandes, T.; Foden, J. Framework for understanding marine ecosystem health. Mar. Ecol. Prog. Ser. 2013, 494, 1-27. [CrossRef]

7. O'Brien, A.; Townsend, K.; Hale, R.; Sharley, D.; Pettigrove, V. How is ecosystem health defined and measured? A critical review of freshwater and estuarine studies. Ecol. Indic. 2016, 69, 722-729. [CrossRef]

8. Li, Z.; Xu, D.; Guo, X. Remote sensing of ecosystem health: Opportunities, challenges, and future perspectives. Sensors 2014, 14, 21117-21139. [CrossRef]

9. Su, M.; Fath, B.D.; Yang, Z. Urban ecosystem health assessment: A review. Sci. Total Environ. 2010, 408, 2425-2434. [CrossRef]

10. Mingers, J.; Leydesdorff, L. A review of theory and practice in scientometrics. Eur. J. Oper. Res. 2015, 246, 1-19. [CrossRef]

11. Staab, S.; Studer, R.; Schnurr, H.-P.; Sure, Y. Knowledge processes and ontologies. IEEE Intell. Syst. 2001, 16, 26-34. [CrossRef]

12. Chen, C.; Song, I.-Y.; Yuan, X.; Zhang, J. The thematic and citation landscape of data and knowledge engineering (1985-2007). Data Knowl. Eng. 2008, 67, 234-259. [CrossRef]

13. Qiu, H.-H.; Liu, L.-G. A study on the evolution of carbon capture and storage technology based on knowledge mapping. Energies 2018, 11, 1103. [CrossRef]

14. Yu, D.; $\mathrm{Xu}, \mathrm{C}$. Mapping research on carbon emissions trading: A co-citation analysis. Renew. Sustain. Energy Rev. 2017, 74, 1314-1322. [CrossRef]

15. Chen, C. Science mapping: A systematic review of the literature. J. Data Inf. Sci. 2017, 2, 1-40. [CrossRef]

16. Jiang, Y.; Hou, L.; Shi, T.; Gui, Q. A review of urban planning research for climate change. Sustainability 2017, 9, 2224. [CrossRef]

17. Huang, X.; Li, H.; Zhang, X.; Zhang, X. Land use policy as an instrument of rural resilience-The case of land withdrawal mechanism for rural homesteads in China. Ecol. Indic. 2018, 87, 47-55. [CrossRef]

18. Shi, S.X.; Tong, P.S. Ananalysis of ecological security of the urban agglomeration development trend based on Cite Space econometric analysis. Acta Ecol. Sin. 2018, 38, 8234-8246.

19. Schaeffer, D.J.; Herricks, E.E.; Kerster, H.W. Ecosystem health: I. Measuring ecosystem health. Environ. Manag. 1988, 12, 445-455. [CrossRef]

20. Rapport, D.J. What constitutes ecosystem health? Perspect. Biol. Med. 1989, 33, 120-132. [CrossRef] 
21. Fang, Y.; Yin, J.; Wu, B. Climate change and tourism: A scientometric analysis using CiteSpace. J. Sustain. Tour. 2017, 26, 108-126. [CrossRef]

22. Chen, C. Searching for intellectual turning points: Progressive knowledge domain visualization. Proc. Natl. Acad. Sci. USA 2004, 101, 5303-5310. [CrossRef] [PubMed]

23. Chen, C. CiteSpace II: Detecting and visualizing emerging trends and transient patterns in scientific literature. J. Am. Soc. Inf. Sci. Technol. 2006, 57, 359-377. [CrossRef]

24. Liu, S.; Sun, Y.P.; Gao, X.L.; Sui, Y. Knowledge domain and emerging trends in Alzheimer's disease: A scientometric review based on CiteSpace analysis. Neural Regen. Res. 2019, 14, 1643-1650. [PubMed]

25. Small, H. Co-citation in the Scientific Literature: A New Measure of the Relationship Between Two Documents. J. Am. Soc. Inf. Sci. 1973, 24, 265-269. [CrossRef]

26. Mustafee, N.; Katsaliaki, K.; Fishwick, P. Exploring the modelling and simulation knowledge base through journal co-citation analysis. Scientometrics 2014, 98, 2145-2159. [CrossRef]

27. Zhu, J.; Hua, W. Visualizing the knowledge domain of sustainable development research between 1987 and 2015: A bibliometric analysis. Scientometrics 2017, 110, 893-914. [CrossRef]

28. Xiao, F.; Li, C.; Sun, J.; Zhang, L. Knowledge domain and emerging trends in organic photovoltaic technology: A scientometric review based on CiteSpace analysis. Front. Chem. 2017, 5, 67. [CrossRef]

29. Burger, J.; Tsipoura, N.; Gochfeld, M.; Greenberg, M.R. Ecological considerations for evaluating current risk and designing long-term stewardship on Department of Energy lands. In Long-Term Management of Contaminated Sites; Emerald Group Publishing Limited: Bingley, UK, 2006; pp. 139-162.

30. Xiang, C.; Wang, Y.; Liu, H. A scientometrics review on nonpoint source pollution research. Ecol. Eng. 2017, 99, 400-408. [CrossRef]

31. Rapport, D.J. Evolution of indicators of ecosystem health. In Ecological Indicators; Springer: Berlin/Heidelberg, Germany, 1992; pp. 121-134.

32. Callicott, J.B.; Crowder, L.B.; Mumford, K. Current normative concepts in conservation. Conserv. Biol. 1999, 13, 22-35. [CrossRef]

33. Fairweather, P.G. Determining the 'health'of estuaries: Priorities for ecological research. Aust. J. Ecol. 1999, 24, 441-451. [CrossRef]

34. Fairweather, P.G. State of environment indicators of 'river health': Exploring the metaphor. Freshw. Biol. 1999, 41, 211-220. [CrossRef]

35. Parkes, M.; Panelli, R. Integrating catchment ecosystems and community health: The value of participatory action research. Ecosyst. Health 2001, 7, 85-106. [CrossRef]

36. Patil, G.; Myers, W.L. Environmental and ecological health assessment of landscapes and watersheds with remote sensing data. Ecosyst. Health 1999, 5, 221-224. [CrossRef]

37. Sherman, K. Sustainability, Biomass Yields, and Health of Coastal Ecosystems: An Ecological Perspective; Marine Ecology Progress Series: Oldendorf, Germany, 1994; Volume 112, pp. 277-301.

38. Sherman, K. Coastal Ecosystem Health A Global Perspective. Ann. N. Y. Acad. Sci. 1994, 740, $24-43$. [CrossRef]

39. Karr, J.R. Defining and measuring river health. Freshw. Biol. 1999, 41, 221-234. [CrossRef]

40. Vora, R.S. Developing programs to monitor ecosystem health and effectiveness of management practices on Lakes States National Forests, USA. Biol. Conserv. 1997, 80, 289-302. [CrossRef]

41. Xu, F.-L.; Dawson, R.W.; Tao, S.; Cao, J.; Li, B.-G. A method for lake ecosystem health assessment: An Ecological Modeling Method (EMM) and its application. Hydrobiologia 2001, 443, 159-175. [CrossRef]

42. Xu, F.; Lam, K.; Zhao, Z.; Zhan, W.; Chen, Y.D.; Tao, S. Marine coastal ecosystem health assessment: A case study of the Tolo Harbour, Hong Kong, China. Ecol. Model. 2004, 173, 355-370. [CrossRef]

43. Aarts, B.G. Ecological sustainability and biodiversity. Int. J. Sustain. Dev. World Ecol. 1999, 6, 89-102. [CrossRef]

44. Xu, F.-L.; Tao, S.; Dawson, R.; Li, B.-G. A GIS-based method of lake eutrophication assessment. Ecol. Model. 2001, 144, 231-244. [CrossRef]

45. Zhang, J.; Jørgensen, S.E.; Tan, C.O.; Beklioglu, M. A structurally dynamic modelling—Lake Mogan, Turkey as a case study. Ecol. Model. 2003, 164, 103-120. [CrossRef]

46. Xu, F.-L.; Tao, S.; Dawson, R.W.; Li, P.-g.; Cao, J. Lake ecosystem health assessment: Indicators and methods. Water Res. 2001, 35, 3157-3167. [CrossRef] 
47. Clapcott, J.E.; Young, R.G.; Goodwin, E.O.; Leathwick, J.R. APPLIED ISSUES: Exploring the response of functional indicators of stream health to land-use gradients. Freshw. Biol. 2010, 55, 2181-2199. [CrossRef]

48. Hladyz, S.; Tiegs, S.D.; Gessner, M.O.; Giller, P.S.; RÎŞNOVEANU, G.; Preda, E.; Nistorescu, M.; Schindler, M.; Woodward, G. Leaf-litter breakdown in pasture and deciduous woodland streams: A comparison among three European regions. Freshw. Biol. 2010, 55, 1916-1929. [CrossRef]

49. Feio, M.; Alves, T.; Boavida, M.; Medeiros, A.; Graça, M. Functional indicators of stream health: A river-basin approach. Freshw. Biol. 2010, 55, 1050-1065. [CrossRef]

50. Bunn, S.; Abal, E.; Smith, M.; Choy, S.; Fellows, C.; Harch, B.; Kennard, M.; Sheldon, F. Integration of science and monitoring of river ecosystem health to guide investments in catchment protection and rehabilitation. Freshw. Biol. 2010, 55, 223-240. [CrossRef]

51. Clapcott, J.E.; Barmuta, L.A. Forest clearance increases metabolism and organic matter processes in small headwater streams. J. N. Am. Benthol. Soc. 2010, 29, 546-561. [CrossRef]

52. Su, M.; Yang, Z.; Chen, B. Relative urban ecosystem health assessment: A method integrating comprehensive evaluation and detailed analysis. Ecohealth 2010, 7, 459-472. [CrossRef]

53. Xia, X.; Huang, G.; Duan, N. An evaluation of dynamic mutuality measurements and methods in cyclic time series. Commun. Nonlinear Sci. Numer. Simul. 2010, 15, 4020-4028. [CrossRef]

54. Zhou, S.; Chen, H.; Li, S. Resources use and greenhouse gas emissions in urban economy: Ecological input-output modeling for Beijing 2002. Commun. Nonlinear Sci. Numer. Simul. 2010, 15, 3201-3231. [CrossRef]

55. Chen, H.; Chen, G.; Ji, X. Cosmic emergy based ecological systems modelling. Commun. Nonlinear Sci. Numer. Simul. 2010, 15, 2672-2700. [CrossRef]

56. Death, R.G.; Death, F.; Stubbington, R.; Joy, M.K.; van den Belt, M. How good are Bayesian belief networks for environmental management? A test with data from an agricultural river catchment. Freshw. Biol. 2015, 60, 2297-2309. [CrossRef]

57. Hartmann, M.; Frey, B.; Mayer, J.; Mäder, P.; Widmer, F. Distinct soil microbial diversity under long-term organic and conventional farming. ISME J. 2015, 9, 1177. [CrossRef] [PubMed]

58. Nichols, S.J.; Barmuta, L.A.; Chessman, B.C.; Davies, P.E.; Dyer, F.J.; Harrison, E.T.; Hawkins, C.P.; Jones, I.; Kefford, B.J.; Linke, S. The imperative need for nationally coordinated bioassessment of rivers and streams. Mar. Freshw. Res. 2017, 68, 599-613. [CrossRef]

59. Lallias, D.; Hiddink, J.G.; Fonseca, V.G.; Gaspar, J.M.; Sung, W.; Neill, S.P.; Barnes, N.; Ferrero, T.; Hall, N.; Lambshead, P.J.D. Environmental metabarcoding reveals heterogeneous drivers of microbial eukaryote diversity in contrasting estuarine ecosystems. ISME J. 2015, 9, 1208. [CrossRef]

60. Wu, W.; Xu, Z.; Zhan, C.; Yin, X.; Yu, S. A new framework to evaluate ecosystem health: A case study in the Wei River basin, China. Environ. Monit. Assess. 2015, 187, 460. [CrossRef]

61. Lakew, A.; Moog, O. A multimetric index based on benthic macroinvertebrates for assessing the ecological status of streams and rivers in central and southeast highlands of Ethiopia. Hydrobiologia 2015, 751, 229-242. [CrossRef]

62. Sun, R.; Yao, P.; Wang, W.; Yue, B.; Liu, G. Assessment of wetland ecosystem health in the Yangtze and Amazon River Basins. ISPRS Int. J. Geo-Inf. 2017, 6, 81. [CrossRef]

63. Higgins, A.; Bryan, B.; Overton, I.; Holland, K.; Lester, R.; King, D.; Nolan, M.; Connor, J. Integrated modelling of cost-effective siting and operation of flow-control infrastructure for river ecosystem conservation. Water Resour. Res. 2011, 47. [CrossRef]

64. Jones, A.R.; Schlacher, T.A.; Schoeman, D.S.; Weston, M.A.; Withycombe, G.M. Ecological research questions to inform policy and the management of sandy beaches. Ocean Coast. Manag. 2017, 148, 158-163. [CrossRef]

65. Wolf, K.L.; Blahna, D.J.; Brinkley, W.; Romolini, M. Environmental stewardship footprint research: Linking human agency and ecosystem health in the Puget Sound region. Urban Ecosyst. 2013, 16, 13-32. [CrossRef]

66. Xie, X.; Pu, L. Assessment of urban ecosystem health based on matter element analysis: A case study of 13 cities in Jiangsu Province, China. Int. J. Environ. Res. Public Health 2017, 14, 940. [CrossRef] [PubMed]

67. Döring, T.F.; Vieweger, A.; Pautasso, M.; Vaarst, M.; Finckh, M.R.; Wolfe, M.S. Resilience as a universal criterion of health. J. Sci. Food Agric. 2015, 95, 455-465. [CrossRef] [PubMed]

68. Doi, H.; Katano, I.; Negishi, J.N.; Sanada, S.; Kayaba, Y. Effects of biodiversity, habitat structure, and water quality on recreational use of rivers. Ecosphere 2013, 4, 1-11. [CrossRef] 
69. Rapport, D.J.; Costanza, R.; McMichael, A. Assessing ecosystem health. Trends Ecol. Evol. 1998, 13, $397-402$. [CrossRef]

70. Vörösmarty, C.J.; McIntyre, P.B.; Gessner, M.O.; Dudgeon, D.; Prusevich, A.; Green, P.; Glidden, S.; Bunn, S.E.; Sullivan, C.A.; Liermann, C.R. Global threats to human water security and river biodiversity. Nature 2010, 467, 555. [CrossRef] [PubMed]

71. Young, R.G.; Matthaei, C.D.; Townsend, C.R. Organic matter breakdown and ecosystem metabolism: Functional indicators for assessing river ecosystem health. J. N. Am. Benthol. Soc. 2008, 27, 605-625. [CrossRef]

72. Suter, G.W. A critique of ecosystem health concepts and indexes. Environ. Toxicol. Chem. Int. J. 1993, 12, 1533-1539. [CrossRef]

73. Poff, N.L.; Zimmerman, J.K. Ecological responses to altered flow regimes: A literature review to inform the science and management of environmental flows. Freshw. Biol. 2010, 55, 194-205. [CrossRef]

74. Ehrenfeld, D.; Costanza, R.; Norton, B.; Haskell, B. Ecosystem Health: New Goals for Environmental Management; Island Press: Washington, DC, USA, 1992.

75. Young, R.G.; Collier, K.J. Contrasting responses to catchment modification among a range of functional and structural indicators of river ecosystem health. Freshw. Biol. 2009, 54, 2155-2170. [CrossRef]

76. Su, M.; Yang, Z.; Chen, B.; Ulgiati, S. Urban ecosystem health assessment based on emergy and set pair analysis-A comparative study of typical Chinese cities. Ecol. Model. 2009, 220, 2341-2348. [CrossRef]

77. Birk, S.; Bonne, W.; Borja, A.; Brucet, S.; Courrat, A.; Poikane, S.; Solimini, A.; Van De Bund, W.; Zampoukas, N.; Hering, D. Three hundred ways to assess Europe's surface waters: An almost complete overview of biological methods to implement the Water Framework Directive. Ecol. Indic. 2012, 18, 31-41. [CrossRef]

78. Poff, N.L.; Richter, B.D.; Arthington, A.H.; Bunn, S.E.; Naiman, R.J.; Kendy, E.; Acreman, M.; Apse, C.; Bledsoe, B.P.; Freeman, M.C. The ecological limits of hydrologic alteration (ELOHA): A new framework for developing regional environmental flow standards. Freshw. Biol. 2010, 55, 147-170. [CrossRef]

79. Halpern, B.S.; Longo, C.; Hardy, D.; McLeod, K.L.; Samhouri, J.F.; Katona, S.K.; Kleisner, K.; Lester, S.E.; O'leary, J.; Ranelletti, M. An index to assess the health and benefits of the global ocean. Nature 2012, 488, 615. [CrossRef]

80. Halpern, B.S.; Walbridge, S.; Selkoe, K.A.; Kappel, C.V.; Micheli, F.; D’agrosa, C.; Bruno, J.F.; Casey, K.S.; Ebert, C.; Fox, H.E. A global map of human impact on marine ecosystems. Science 2008, 319, 948-952. [CrossRef] [PubMed]

81. Costanza, R. Ecosystem health and ecological engineering. Ecol. Eng. 2012, 45, 24-29. [CrossRef]

82. Costanza, R.; de Groot, R.; Sutton, P.; Van der Ploeg, S.; Anderson, S.J.; Kubiszewski, I.; Farber, S.; Turner, R.K. Changes in the global value of ecosystem services. Glob. Environ. Chang. 2014, 26, 152-158. [CrossRef]

83. Hering, D.; Borja, A.; Carstensen, J.; Carvalho, L.; Elliott, M.; Feld, C.K.; Heiskanen, A.-S.; Johnson, R.K.; Moe, J.; Pont, D. The European Water Framework Directive at the age of 10: A critical review of the achievements with recommendations for the future. Sci. Total Environ. 2010, 408, 4007-4019. [CrossRef]

84. Woodward, G.; Gessner, M.O.; Giller, P.S.; Gulis, V.; Hladyz, S.; Lecerf, A.; Malmqvist, B.; McKie, B.G.; Tiegs, S.D.; Cariss, H. Continental-scale effects of nutrient pollution on stream ecosystem functioning. Science 2012, 336, 1438-1440. [CrossRef]

85. Karr, J.R. Using biological criteria to protect ecological health. In Evaluating and Monitoring the Health of Large-Scale Ecosystems; Springer: Berlin/Heidelberg, Germany, 1995; pp. 137-152.

86. Woodwell, G.M. The Earth in Transition: Patterns and Processes of Biotic Impoverishment; Cambridge University Press: Cambridge, UK, 1990.

87. Karr, J.R.; Chu, E.W. Ecological integrity: Reclaiming lost connections. In Perspectives on Ecological Integrity; Springer: Berlin/Heidelberg, Germany, 1995; pp. 34-48.

88. Rapport, D.J. Ecosystem Health: Exploring the Territory; University of Guelph: Guelph, ON, Canada, 1995.

89. Costanza, R.; d'Arge, R.; De Groot, R.; Farber, S.; Grasso, M.; Hannon, B.; Limburg, K.; Naeem, S.; O'neill, R.V.; Paruelo, J. The value of the world's ecosystem services and natural capital. Nature 1997, 387, 253. [CrossRef]

90. Bonada, N.; Prat, N.; Resh, V.H.; Statzner, B. Developments in aquatic insect biomonitoring: A comparative analysis of recent approaches. Annu. Rev. Entomol. 2006, 51, 495-523. [CrossRef] [PubMed] 
91. Davies, P. Development of a national river bioassessment system (AUSRIVAS) in Australia. In Assessing the Biological Quality of Fresh Waters: RIVPACS and Other Techniques, Proceedings of the International Workshop held in Oxford, UK, 16-18 September 1997; Freshwater Biological Association (FBA): Ambleside, Cumbria, UK, 2000; pp. 113-124.

92. Gessner, M.O.; Chauvet, E. A case for using litter breakdown to assess functional stream integrity. Ecol. Appl. 2002, 12, 498-510. [CrossRef]

93. Sandin, L.; Solimini, A.G. Freshwater ecosystem structure-function relationships: From theory to application. Freshw. Biol. 2009, 54, 2017-2024. [CrossRef]

94. Feld, C.K.; Birk, S.; Bradley, D.C.; Hering, D.; Kail, J.; Marzin, A.; Melcher, A.; Nemitz, D.; Pedersen, M.L.; Pletterbauer, F. From natural to degraded rivers and back again: A test of restoration ecology theory and practice. In Advances in Ecological Research; Elsevier: Amsterdam, The Netherlands, 2011; Volume 44, pp. 119-209.

95. Dudgeon, D.; Arthington, A.H.; Gessner, M.O.; Kawabata, Z.-I.; Knowler, D.J.; Lévêque, C.; Naiman, R.J.; Prieur-Richard, A.-H.; Soto, D.; Stiassny, M.L. Freshwater biodiversity: Importance, threats, status and conservation challenges. Biol. Rev. 2006, 81, 163-182. [CrossRef]

96. Wagenhoff, A. Multiple-Stressor Effects Along Gradients of Deposited Fine Sediment and Dissolved Nutrients in Streams. Ph.D. Thesis, University of Otago, Dunedin, New Zealand, 2011.

97. Allan, J.D. Landscapes and riverscapes: The influence of land use on stream ecosystems. Annu. Rev. Ecol. Evol. Syst. 2004, 35, 257-284. [CrossRef]

98. Dewson, Z.S.; James, A.B.; Death, R.G. A review of the consequences of decreased flow for instream habitat and macroinvertebrates. J. N. Am. Benthol. Soc. 2007, 26, 401-415. [CrossRef]

99. Palmer, M.A.; Reidy Liermann, C.A.; Nilsson, C.; Flörke, M.; Alcamo, J.; Lake, P.S.; Bond, N. Climate change and the world's river basins: Anticipating management options. Front. Ecol. Environ. 2008, 6, 81-89. [CrossRef]

100. Carpenter, S.R.; Ludwig, D.; Brock, W.A. Management of eutrophication for lakes subject to potentially irreversible change. Ecol. Appl. 1999, 9, 751-771. [CrossRef]

101. Forbes, A.; Richardson, R.E. Studies on the biology of the upper Illinois River. Ill. Nat. Hist. Surv. Bull. 1913, 9, 481-574.

102. Zinger, L.; Boetius, A.; Ramette, A. Bacterial taxa-area and distance-decay relationships in marine environments. Mol. Ecol. 2014, 23, 954-964. [CrossRef] [PubMed] 